\title{
RESPOSTAS TERMORREGULADORAS DE MATRIZES SUÍNAS HÍBRIDAS EM LACTAÇÃO, MANTIDAS EM AMBIENTE QUENTE ${ }^{1}$
}

\author{
Thermoregulator answers of hybrid female swine in lactation, maintained in hot environment
}

\author{
Terezinha Domiciano Dantas Martins ${ }^{2}$, Alberto Neves Costa ${ }^{3}$, José Humberto Vilar Da Silva ${ }^{4}$
}

\begin{abstract}
RESUMO
Objetivou-se avaliar a adaptabilidade fisiológica de 73 matrizes suínas híbridas em lactação ao ambiente quente. As fêmeas foram distribuídas em delineamento inteiramente casualizado, num esquema fatorial de $5 \mathrm{x} 4 \mathrm{x} 4$, sendo, cinco ordens de parto - OP $\left(1^{\mathrm{a}}, 2^{\mathrm{a}}, 3^{\mathrm{a}}, 4^{\mathrm{a}} \mathrm{e} \geq 5^{\mathrm{a}}\right)$, quatro momentos em relação ao parto (quatro dias antes e 3,10 e $17^{\mathrm{o}}$ dia depois) e quatro horas do dia $(8,12$, 16 e 20 h). A temperatura retal (TR) oscilou com a hora do dia, a OP, e o momento de avaliação, sendo maior às 16 h, em primíparas e na fase inicial da lactação. A freqüência respiratória permaneceu elevada, principalmente entre as 12 e $16 \mathrm{~h}$ do dia em fêmeas jovens. Conclui-se que o calor intenso entre 12 e $16 \mathrm{~h}$ conduz aos animais ao desconforto térmico, sendo as primíparas a categoria de menor adaptabilidade.
\end{abstract}

Termos para indexação: Adaptabilidade, frequência respiratória, temperatura retal.

\section{ABSTRACT}

The aim was to assess the physiological adaptability of 73 hybrid female swine in lactation in the hot climate. The females of $1^{\text {st }}, 2^{\text {nd }}, 3^{\text {rd }}, 4^{\text {th }}$, and $5^{\text {th }}$ parturition orders $(\mathrm{PO})$ were used, distributed in a completely randomized outline, in a factorial arrangement of $5 \times 4 \times 4$, being five PO $\left(1^{\text {st }}, 2^{\text {nd }}, 3^{\text {rd }}, 4^{\text {th }}\right.$, and $\left.5^{\text {th }}\right)$, four moments in relation to the delivery (four days before, and on the $3^{\text {rd }}, 10^{\text {th }}$ and $17^{\text {th }}$ day after), and four hours a day $(8,12,16$ and $20 \mathrm{~h})$. The rectal temperature oscillated according to the hour of day, the PO, and the moment of evaluation, being greater at $16 \mathrm{~h}$, in primiparous, and in the initial phase of lactation. The breathing frequency remained elevated, mainly between 12 and $16 \mathrm{~h}$, in young females. One concluded that the intense heat between 12 and $16 \mathrm{~h}$ leads the animals to the thermal discomfort, mainly the category of smaller adaptability.

Index terms: Adaptability, breathing frequency, rectal temperature.

(Recebido em 8 de novembro de 2006 e aprovado em 19 de setembro de 2007)

\section{INTRODUÇÃO}

A suinocultura passou por uma série de transformações nas últimas décadas, devido, principalmente, aos avanços registrados na genética e na nutrição. Mas, recentemente, o controle das condições ambientais tornou-se uma preocupação mundial, no sentido de promover o bem-estar dos animais e maximizar a produção.

Para matrizes suínas em lactação, a zona de conforto situa-se entre 12 e $22^{\circ} \mathrm{C}$ (BLACK et al., 1993). Nessas condições, a temperatura retal permanece com valores médios de $38,6^{\circ} \mathrm{C}$ e frequiência respiratória ente 26 a 27 mov/min (QUINIOU \& NOBLET, 1999). Porém, quando submetidas a temperaturas ambientais elevadas, as matrizes manifestam desconforto, modificando seu comportamento e desencadeando mecanismos controladores ligados, diretamente, às respostas fisiológicas, na tentativa de dissipar o calor e manter a homeostase térmica. Em conseqüência, são verificadas reduções no consumo alimentar voluntário, perda de peso e da condição corporal, baixo desempenho das matrizes e suas leitegadas ao desmame, e falhas reprodutivas subseqüentes.

Estudo desenvolvido em câmaras climáticas revelou que as matrizes respondem imediatamente ao estresse calórico aumentando as temperaturas do reto, da pele e das glândulas mamárias, e, respiram com uma maior freqüência para tentar facilitar o resfriamento das vias respiratórias e a perda de calor evaporativo (RENAUDEAU et al., 2001). Por outro lado, quando a exposição foi feita por um período de tempo mais longo, os animais demonstraram um ajuste fisiológico sugestivo de um processo de aclimatação (SPENCER et al., 2003).

\footnotetext{
${ }^{1}$ Parte da Tese de Doutorado do primeiro autor

2Doutora em Produção Animal, Professora - Departamento de Agropecuária/DAP - Centro de Ciências Humanas, Sociais e Agrárias - Universidade Federal da Paraíba/UFPB - Cidade Universitária, Campus III - 58220-000 - Bananeiras, PB - domidantas@yahoo.com.br ${ }^{3}$ Ph. D., Professor, Pesquisador CNPq - Universidade Federal do Rio Grande do Norte/UFRN - Centro Universitário - Lagoa Nova - Cx. P. 1524 29072-970 - Natal, RN - ancosta1@bol.com.br

${ }^{4}$ Doutor - Departamento de Agropecuária/DAP - Centro de Ciências Sociais, Humanas e Agrárias - Universidade Federal da Paraíba/UFPB Cidade Universitária, Campus III - 58220-000 - Bananeiras, PB - vilardasilva@yahoo.com.br
} 
Nos Estados Unidos, estima-se uma perda anual entre 300 a 316 milhões de dólares (SAINT PIERRE et al., 2004) em decorrência da incidência sazonal de temperaturas ambientais elevadas, e essas perdas podem ser mais acentuadas em países situados em zonas tropicais, como o Brasil, onde a temperatura ambiente, a umidade relativa do ar e a radiação solar encontram-se na maior parte do ano, acima dos valores recomendados para a criação de suínos. As principais companhias de genética suína disponibilizam fêmeas provenientes de programas de melhoramento desenvolvidos na América do Norte e na Europa, geralmente sob condições de climas temperado e subtropical, com controle otimizado do ambiente térmico, sem propiciar uma resposta clara da adaptação desses animais ao clima tropical.

Como existe relação entre a genética e o meioambiente, é possível que as matrizes de linhagens híbridas apresentem reações diferentes. Entretanto, o conhecimento dessas interações em animais criados em regiões de climas tropicais, como o Brasil, ainda é pouco difundido. A pesquisa foi conduzida para avaliar as respostas termorreguladoras (temperatura retal e frequiência respiratória) de matrizes suínas híbridas em lactação, mantidas em condições ambientais de verão, no Nordeste Brasileiro.

\section{MATERIAL E MÉTODOS}

O experimento foi conduzido em uma granja de suínos localizada no município de Paudalho, Zona da Mata Setentrional Pernambucana, situado a $7^{\circ} 55^{\prime} 58,3^{\prime \prime}$ de LS e $35^{\circ} 8^{\prime} 12,8^{\prime \prime}$ de LO, e a uma altitude de 70m, apresentando clima quente e úmido.

Foram utilizadas 73 fêmeas suínas híbridas (C40) de $1,2,3,4$ e $\geq 5^{\text {a }}$ ordem de parição (OP). As matrizes foram avaliadas em quatro momentos, em relação ao parto (quatro dias antes e no 3,10 e $17^{\circ}$ dia após) e em quatro horários do dia $(8,12,16$ e $20 \mathrm{~h})$.

As matrizes foram alojadas em gaiolas individuais instaladas em sala de maternidade construídas no sentido Leste-Oeste, com paredes laterais abertas e muretas de $0,75 \mathrm{~m}$ altura. Possuiam pé-direito com lanternim $(30 \mathrm{~cm}) \mathrm{e}$ cobertura com telhas de fibro-cimento $(6 \mathrm{~mm})$, pintadas externamente com tinta reflectiva. O galpão possuía cortinas nas paredes laterais, que eram geralmente abertas às $7 \mathrm{~h} 30$ min e fechadas às 18 h. Os três ventiladores (1.730 rpm), localizados nas laterais da sala, eram acionados, rotineiramente, das 11 até às $16 \mathrm{~h}$.

Os dados de temperaturas do globo negro e de bulbo seco/úmido foram verificados em termômetro de globo negro, instalado no centro da sala a uma altura de $1,00 \mathrm{~m}$ do piso da gaiola, e em termohigrômetro de máxima e mínima, localizado na lateral interna. Os dados obtidos através de leituras efetuadas, diariamente, nos horários de $8,12,16$ e 20 horas foram utilizados para determinação da umidade relativa do ar (UR) e do índice de temperatura de globo e umidade (ITGU) de acordo com Buffington et al. (1981).

As fêmeas foram alimentadas com uma ração de lactação contendo $4.725 \mathrm{kcal} / \mathrm{kg}$ EB e $19,79 \%$ PB. No dia do parto, os animais receberam $2 \mathrm{~kg}$ e, depois, foi acrescentado $0,5 \mathrm{~kg} / \mathrm{dia} / \mathrm{matriz}$, divididos em tratos realizados às 7, 14 e 21 horas. As leitegadas foram uniformizadas e equalizadas em 10 ou 11 leitões, 48 horas após o parto.

A medição da temperatura retal - TR $\left({ }^{\circ} \mathrm{C}\right)$ foi feita com os animais em repouso, usando-se um termômetro veterinário $\left( \pm 0,1^{\circ} \mathrm{C}\right)$ o qual teve seu termissor inserido no reto dos animais, por 2 minutos. A freqüência respiratória FR (mov/min) foi obtida através da observação e contagem dos movimentos do flanco durante 15 segundos, e realizada a correção para um minuto. O tempo usado em cada avaliação foi aferido por cronômetro.

$\mathrm{O}$ delineamento foi o inteiramente casualizado, em esquema fatorial $5 \times 4 \times 4$ (cinco OP x quatro momentos em relação ao parto x quatro horas do dia), com número desigual de animais por tratamento. As interações entre os fatores principais foram avaliadas pelo teste de $\mathrm{F}(5 \%)$, e quando significativas, os efeitos dos fatores principais foram estudados dentro de cada nível de outro fator, separadamente pelo teste de Tukey (5\%) conforme proposto por Gomes (1985). Os efeitos dos fatores principais foram avaliados pelos modelos de regressão quadrático e cúbico considerando-se, na escolha do modelo, o nível de significância e o maior valor do coeficiente de determinação $\left(\mathrm{R}^{2}\right)$. Foi realizada análise de correlação para a TR e FR, em função das variáveis ambientais, e a significância dos coeficientes de correlação foi determinada pelo teste $\mathrm{t}$ de Student. As análises estatísticas foram realizadas pelo programa SAS (SAS INSTITUTE, 1997).

\section{RESULTADOS E DISCUSSÃO}

Foram verificadas médias de $27,8^{\circ} \mathrm{C}( \pm 2,23)$ para temperatura do ar, $28,1^{\circ} \mathrm{C}( \pm 2,97)$ para a temperatura do globo, 75,3\% ( $\pm 11,96)$ de umidade relativa do ar e 77,5 $( \pm$ 2,94) de ITGU (Tabela 1 ), com $32^{\circ} \mathrm{C}$ e $24^{\circ} \mathrm{C}$ para as temperaturas ambientais máximas e mínimas, respectivamente. Dessa forma, pôde-se inferir que o ambiente térmico estava inadequado, em todos os horários do dia, uma vez que a temperatura ambiente ultrapassou os 18 a $20^{\circ} \mathrm{C}$ (BLACK et al., 1993) e os 72 de ITGU (TURCO 
et al., 1998) sugeridos para manutenção do conforto térmico de matrizes suínas.

Observou-se diferença entre os tratamentos para a temperatura retal $(\mathrm{TR})$, com interação $(\mathrm{P}<0,05)$ entre a ordem de parto (OP) e o momento em relação ao parto (Tabela 2). Em todas as OP, foram verificadas TR inferiores antes do parto em relação ao período de lactação. A maior atividade metabólica na fase de lactação, com aumento do consumo alimentar e síntese de leite, é a melhor explicação para o aumento da produção de calor corporal nessa fase, em comparação com o período anterior ao parto. Comportamento fisiológico semelhante foi observado por Renaudeau et al. (2001) em matrizes em condições de termoneutralidade.

Após o parto, as primíparas apresentaram TR elevada na primeira avaliação $(\mathrm{P}<0,05)$. Entretanto, a TR variou de acordo com a OP, observando-se efeito cúbico $(\mathrm{P}<0,05)$ do momento em relação ao parto dentro da $1^{\mathrm{a}}, 3^{\mathrm{a}} \mathrm{e}$ $4^{\mathrm{a}} \mathrm{OP}$, e efeito quadrático $(\mathrm{P}<0,05)$ para as demais $\mathrm{OP}$ avaliadas (Figura 1). Esses resultados parecem concordar com a afirmativa de Göransson (1989) e Kelly \& Curtis (1978), de que ocorre uma elevação transitória da TR em porcas após o parto, com as primíparas apresentando os maiores valores, seguida de uma tendência de redução da mesma, com o aumento da OP.

A TR aumentou $(\mathrm{P}<0,05)$ no decorrer das horas do dia (Tabela 3). Esse efeito foi causado pela variação diária da temperatura ambiente (Tabela 1), que incrementou o calor corporal das fêmeas, concomitante aos picos de calor verificados nos horários de 12 e 16 h, porém, essa hipertermia foi transitória. Todavia, o padrão fisiológico observado foi bastante sugestivo de situações pósestresse calórico, em que as matrizes híbridas, em lactação, exigem algum tempo para reduzir a TR em níveis mais próximos de $38,6^{\circ} \mathrm{C}$, propostos por Quiniou \& Noblet (1999) para manter a homeotermia.

Tabela 1 - Valores médios da temperatura ambiente (Ta) e do globo (Tg), valores absolutos da temperatura máxima (TMX) e mínima (TMN), umidade relativa do ar (UR) e índice de temperatura de globo e umidade (ITGU), em função da hora do dia.

\begin{tabular}{|c|c|c|c|c|c|c|}
\hline \multirow{2}{*}{ Hora do dia } & \multicolumn{4}{|c|}{ Temperatura do ar $\left({ }^{\circ} \mathrm{C}\right)$} & \multirow{2}{*}{$\mathrm{UR}(\%)$} & \multirow{2}{*}{ ITGU } \\
\hline & $\mathrm{Ta}\left({ }^{\circ} \mathrm{C}\right)$ & $\operatorname{Tg}\left({ }^{\circ} \mathrm{C}\right)$ & TMX & TMN & & \\
\hline 08 & 26,7 & 28,3 & - & - & 80,3 & 77,6 \\
\hline 12 & 30,4 & 31,7 & - & - & 63,5 & 81,1 \\
\hline 16 & 28,7 & 28,2 & - & - & 71,7 & 77,6 \\
\hline 20 & 25,3 & 24,3 & - & - & 85,6 & 73,6 \\
\hline Média diária & 27,8 & 28,1 & 32,0 & 24,0 & 75,3 & 77,5 \\
\hline $\mathrm{CV}$ & 3,53 & 0,44 & 0,56 & 1,32 & 10,33 & 1,59 \\
\hline
\end{tabular}

Tabela 2 - Média da temperatura retal $\left({ }^{\circ} \mathrm{C}\right)$ de matrizes suínas hibridas, em função da interação entre ordem do parto e momento em relação ao parto.

\begin{tabular}{|c|c|c|c|c|c|}
\hline \multirow[b]{2}{*}{ Ordem do parto } & \multicolumn{4}{|c|}{ Momentos em relação ao parto(dias $)^{1}$} & \multirow[b]{2}{*}{ Média } \\
\hline & -4 & $3^{\circ}$ & $10^{\circ}$ & $17^{\circ}$ & \\
\hline $1^{\mathrm{a}^{2}}$ & $38,66 \pm 0,65 b$ & $40,16 \pm 0,75 \mathrm{a}$ & $39,85 \pm 0,67 \mathrm{a}$ & $39,44 \pm 0,67 b$ & 39,53 \\
\hline $2^{\mathrm{a}^{3}}$ & $39,01 \pm 1,09 \mathrm{a}$ & $39,89 \pm 0,90 \mathrm{~b}$ & $39,86 \pm 0,54 \mathrm{a}$ & $39,71 \pm 0,75$ a & 39,62 \\
\hline $3^{\mathrm{a}^{2}}$ & $38,31 \pm 0,56 \mathrm{c}$ & $39,45 \pm 0,72 \mathrm{c}$ & $39,38 \pm 0,64 b$ & $39,06 \pm 0,59 \mathrm{c}$ & 39,05 \\
\hline $4^{\mathrm{a} 2}$ & $38,53 \pm 0,52 \mathrm{bc}$ & $39,29 \pm 0,79 \mathrm{~cd}$ & $39,09 \pm 0,70 \mathrm{~b}$ & $39,11 \pm 0,55 \mathrm{c}$ & 39,01 \\
\hline$\geq 5^{\mathrm{a} 3}$ & $38,43 \pm 0,50 \mathrm{cb}$ & $39,12 \pm 0,67 \mathrm{~d}$ & $39,14 \pm 0,47 \mathrm{~b}$ & $38,76 \pm 0,48 \mathrm{~d}$ & 38,86 \\
\hline Média & 38,59 & 39,58 & 39,46 & 39,22 & 39,21 \\
\hline
\end{tabular}

${ }^{1}$ Os números: $-4,3^{\circ}, 10^{\circ}$ e $17^{\circ}$, corresponderam os momentos em relação ao parto (dias) em que foram realizadas as mensurações, sendo o parto o dia 0 .

Médias seguidas da mesma letra (colunas) não diferem significativamente entre si pelo teste de Tukey $(\mathrm{P}<0,05)$.

${ }^{2}$ Efeito cúbico $(\mathrm{P}<0,05)$

${ }^{3}$ Efeito quadrático $(\mathrm{P}<0,05)$ 


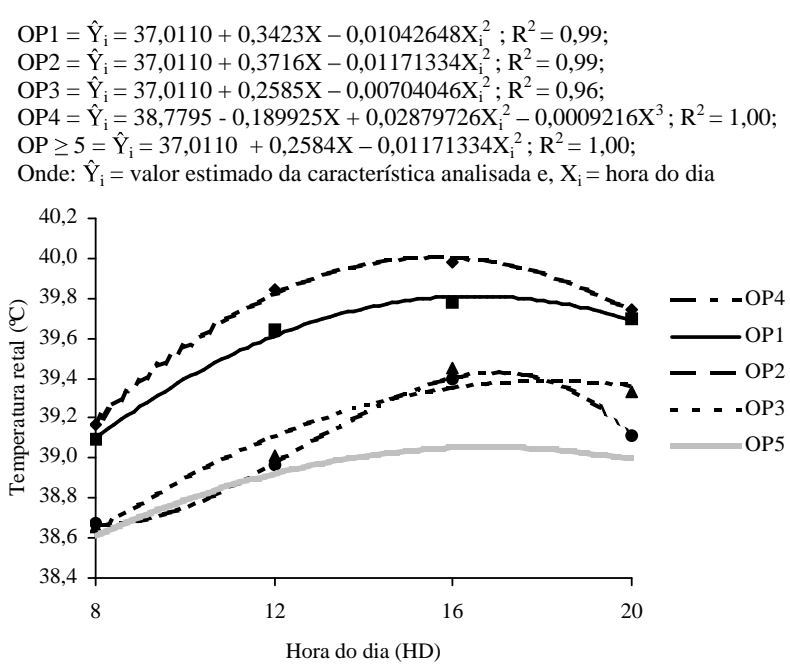

Figura 1 - Temperatura retal $\left({ }^{\circ} \mathrm{C}\right)$ de matrizes suínas híbridas, em função do efeito do momento em relação ao parto em que foi realizada a mensuração dentro da ordem do parto.

Tabela 3 - Temperatura retal $\left({ }^{\circ} \mathrm{C}\right)$ de matrizes suínas híbridas mantidas sob condições de temperatura ambiente elevada, em função da hora do dia.

\begin{tabular}{ccccc}
\hline & \multicolumn{4}{c}{ Hora do dia (h) } \\
\cline { 2 - 5 } & 8 & 12 & 16 & 20 \\
\hline Temperatura & $38,8 \pm$ & $39,2 \pm$ & $39,5 \pm$ & $39,4 \pm$ \\
retal & $0,71 \mathrm{~d}$ & $0,78 \mathrm{c}$ & $0,84 \mathrm{a}$ & $0,78 \mathrm{~b}$ \\
\hline
\end{tabular}

Médias seguidas da mesma letra, não diferem significativamente entre si pelo teste de Tukey $(\mathrm{P}<0,05)$

Na Figura 2, observa-se efeito quadrático $(\mathrm{P}<0,05)$ da hora do dia sobre a TR em função das ordens de parto $1^{\mathrm{a}}, 2^{\mathrm{a}}, 3^{\mathrm{a}} \mathrm{e} \geq 5^{\mathrm{a}}$. Para matrizes de quarto parto, a TR foi melhor representada por uma curva de regressão cúbica $(\mathrm{P}<0,05)$.

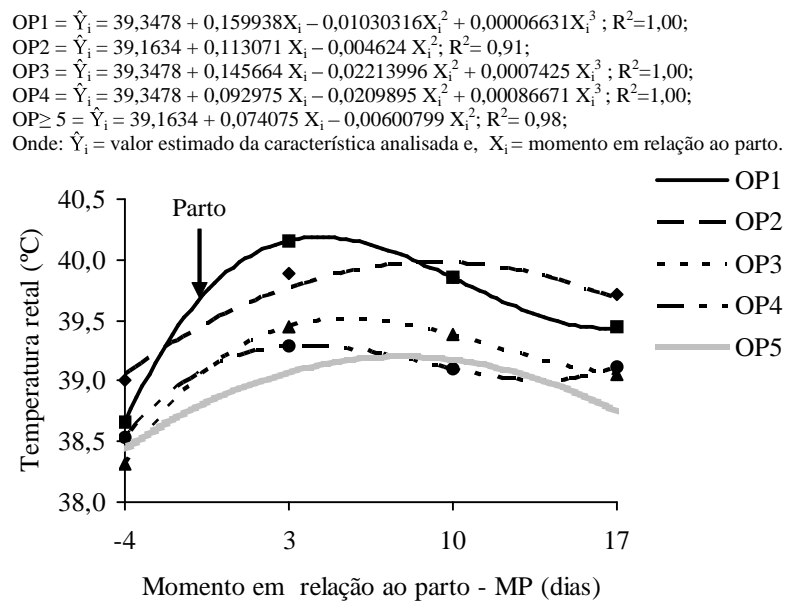

Figura 2-Temperatura retal $\left({ }^{\circ} \mathrm{C}\right)$ de matrizes suínas híbridas, em função do efeito da hora do dia, em que foi realizada a mensuração dentro da ordem do parto.

Verificou-se efeito de interação entre o momento em que a TR foi colhida em relação ao parto e as horas do dia em que foram realizadas as mensurações (Tabela 4). Em todos os momentos, as mensurações realizadas de $8 \mathrm{~h}$ foram menores $(\mathrm{P}<0,05)$, em relação àquelas verificadas nas outras horas do dia, mesmo quando já era observada uma elevação na temperatura ambiente (Tabela 1). Esses resultados sugerem que o ambiente térmico no período noturno estava mais adequado aos animais, mesmo quando a temperatura ambiente atingiu $24^{\circ} \mathrm{C}$.

A análise de regressão demonstrou que o efeito do momento em relação ao parto sobre a TR foi cúbico $(\mathrm{P}<0,05)$ às 8 e 12 h, e quadrático $(\mathrm{P}<0,05)$ às 16 e 20 h (Figura 3$)$.

Tabela 4 - Média da temperatura retal $\left({ }^{\circ} \mathrm{C}\right)$ de matrizes suínas híbridas em função da interação entre momento em relação ao parto e hora do dia.

\begin{tabular}{cccccc}
\hline \multirow{2}{*}{$\begin{array}{c}\text { Momentos em relação ao } \\
\text { parto (dias) }\end{array}$} & \multicolumn{4}{c}{ Hora do dia } & Média \\
\cline { 2 - 5 } & $8^{2}$ & $12^{2}$ & $16^{3}$ & $20^{3}$ & \\
\hline-4 & $38,20 \pm 0,54 \mathrm{c}$ & $38,59 \pm 0,62 \mathrm{~b}$ & $38,92 \pm 0,72 \mathrm{a}$ & $38,55 \pm 0,59 \mathrm{~b}$ & 38,56 \\
$3^{\mathbf{o}}$ & $39,19 \pm 0,75 \mathrm{c}$ & $39,61 \pm 0,84 \mathrm{~b}$ & $39,83 \pm 0,91 \mathrm{a}$ & $39,72 \pm 0,79 \mathrm{ab}$ & 39,59 \\
$10^{\circ}$ & $39,03 \pm 0,62 \mathrm{c}$ & $39,38 \pm 0,66 \mathrm{~b}$ & $39,73 \pm 0,72 \mathrm{a}$ & $39,63 \pm 0,61 \mathrm{a}$ & 39,44 \\
$17^{\mathbf{o}}$ & $38,74 \pm 0,49 \mathrm{~b}$ & $39,24 \pm 0,66 \mathrm{a}$ & $39,43 \pm 0,72 \mathrm{a}$ & $39,39 \pm 0,60 \mathrm{a}$ & 39,20 \\
Média & 38,79 & 39,20 & 39,48 & 39,32 & 39,20 \\
\hline
\end{tabular}

${ }^{1}$ Os números: $-4,3^{\circ}, 10^{\circ}$ e $17^{\circ}$, corresponderam os momentos em relação ao parto (dias) em que foram realizadas as mensurações, sendo o parto o dia 0 .

Médias seguidas da mesma letra (linhas), não diferem significativamente entre si pelo teste de Tukey $(\mathrm{P}<0,05)$.

${ }^{2}$ Efeito cúbico $(\mathrm{P}<0,05)$

${ }^{3}$ Efeito quadrático $(\mathrm{P}<0,05)$ 


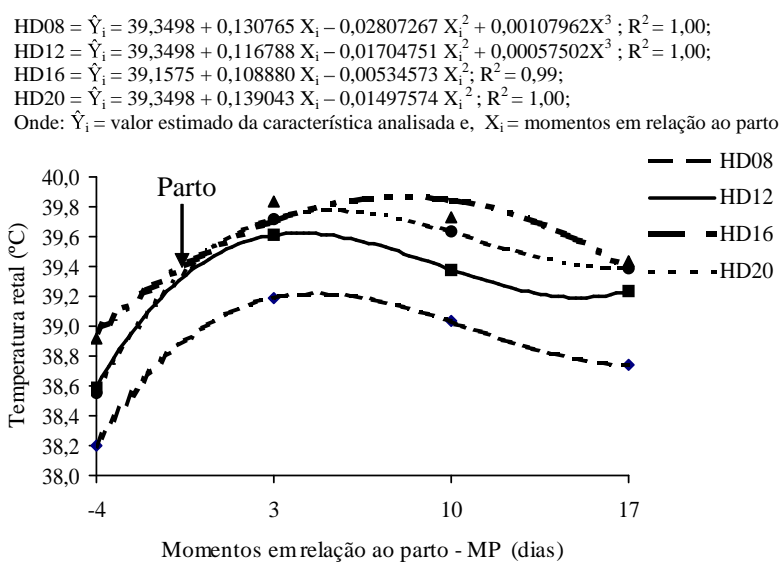

Figura 3 - Temperatura retal $\left({ }^{\circ} \mathrm{C}\right)$ de matrizes suínas híbridas, em função do efeito do momento em relação ao parto dentro da hora do dia (HD) em que foi realizada a mensuração.

Observou-se que a hora do dia apresentou efeito quadrático $(\mathrm{P}<0,05)$ sobre a TR nos quatro momentos avaliados, com as maiores e menores ocorrendo de 12 às 16 h, e de 8 às $20 \mathrm{~h}$, respectivamente, com picos em torno de 16 h (Figura 4). Considerando todas as OP, a TR média diária verificada, durante a lactação, $\left(39,2^{\circ} \mathrm{C}\right)$ ficou abaixo de $39,4^{\circ} \mathrm{C}$ (QUINIOU \& NOBLET, 1999) e $39,5^{\circ} \mathrm{C}$ (RENAUDEAU et al., 2001) observado em matrizes mantidas em ambientes com temperatura elevada em câmaras climáticas, ou de 39,35 ${ }^{\circ} \mathrm{C}$ (TURCO et al., 1998), em condições de ambiente natural do Brasil.

Para a frequiência respiratória - FR $(\mathrm{CV}=43,53 \%)$ houve interação $(\mathrm{P}<0,05)$ entre a OP e o momento da realização da observação em relação ao parto. Quatro dias antes do parto, a FR apresentou-se estável, independente da OP, mas foi mais elevada nas fêmeas jovens (Tabela 5). Provavelmente, esse resultado está associado à maior taxa metabólica em relação ao peso corporal por causa da gestação e o crescimento final das próprias fêmeas nessa fase. Entretanto, Kelly \& Curtis (1978) não verificaram efeito da OP sobre a FR.

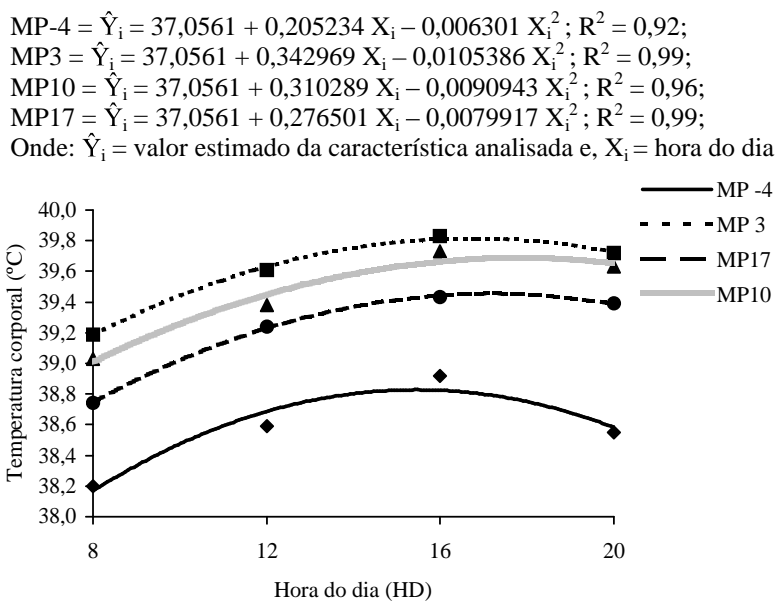

Figura 4-Temperatura retal $\left({ }^{\circ} \mathrm{C}\right)$ de matrizes suínas híbridas, em função do efeito da hora do dia (HD) dentro do momento em relação ao parto (MP).

A $2^{\mathrm{a}}$ e $5^{\mathrm{a}}$ OP afetou de forma cúbica $(\mathrm{P}<0,05)$ e a $\mathrm{OP}$ $1^{\mathrm{a}}$ de forma quadrática $(\mathrm{P}<0,05)$ a $\mathrm{FR}$ das porcas (Figura 5). Spencer et al. (2003) também verificaram aumento imediato da FR, que declinou progressivamente com o avanço da curva de lactação, sugerindo a aclimatação dos animais. Porém, em outros estudos a FR não foi modificada durante

Tabela 5 - Médias da freqüência respiratória (mov/min) de matrizes suínas hibridas em função da interação entre momento em relação ao parto e ordem do parto.

\begin{tabular}{|c|c|c|c|c|c|c|}
\hline \multirow{2}{*}{$\begin{array}{l}\text { Momento em } \\
\text { relação ao parto } \\
(\text { dias })^{1}\end{array}$} & \multicolumn{5}{|c|}{ Ordem do parto } & \multirow[b]{2}{*}{ Média } \\
\hline & $1^{\mathrm{a}^{2}}$ & $2^{a^{3}}$ & $3^{a}$ & $4^{\mathrm{a}}$ & $\geq 5^{\mathrm{a}^{3}}$ & \\
\hline-4 & $81,75 \pm 41,24 a$ & $86,96 \pm 35,70 \mathrm{a}$ & $79,02 \pm 34,26 a$ & $75,81 \pm 31,99 a$ & $68,70 \pm 30,31 \mathrm{a}$ & 78,45 \\
\hline $3^{\circ}$ & $92,23 \pm 40,10 \mathrm{a}$ & $70,33 \pm 46,07 b$ & $72,40 \pm 32,84 b$ & $67,46 \pm 36,04 b$ & $54,22 \pm 30,41 \mathrm{c}$ & 71,33 \\
\hline $10^{\circ}$ & $87,58 \pm 34,52 \mathrm{a}$ & $94,67 \pm 40,79 a$ & $70,89 \pm 32,18 b$ & $70,21 \pm 33,69 b$ & $67,89 \pm 33,11 b$ & 78,25 \\
\hline $17^{\circ}$ & $67,76 \pm 67,76 b$ & $90,83 \pm 37,13 a$ & $71,18 \pm 28,72 b$ & $72,75 \pm 34,71 \mathrm{~b}$ & $54,54 \pm 27,43 \mathrm{c}$ & 71,41 \\
\hline Média & 82,33 & 85,70 & 73,37 & 71,56 & 61,34 & 74,86 \\
\hline
\end{tabular}

${ }^{1}$ Os números: $-4,3^{\circ}, 10^{\circ}$ e $17^{\circ}$, corresponderam os momentos em relação ao parto (dias) em que foram realizadas as mensurações, sendo o parto o dia 0 .

Médias seguidas da mesma letra (linhas), não diferem significativamente entre si pelo teste de Tukey $(\mathrm{P}<0,05)$.

${ }^{2}$ Efeito quadrático $(\mathrm{P}<0,05)$

${ }^{3}$ Efeito cúbico $(\mathrm{P}<0,05)$ 
a lactação, permanecendo em níveis de $124 \mathrm{mov} / \mathrm{min}$ (QUINIOU \& NOBLET, 1999) e 105 mov/min (RENAUDEAU et al., 2001), quando as matrizes foram mantidas em ambientes quentes $\left(29^{\circ} \mathrm{C}\right)$, sendo bastante superiores à média de 74,2 mov/min, detectada nesse trabalho.

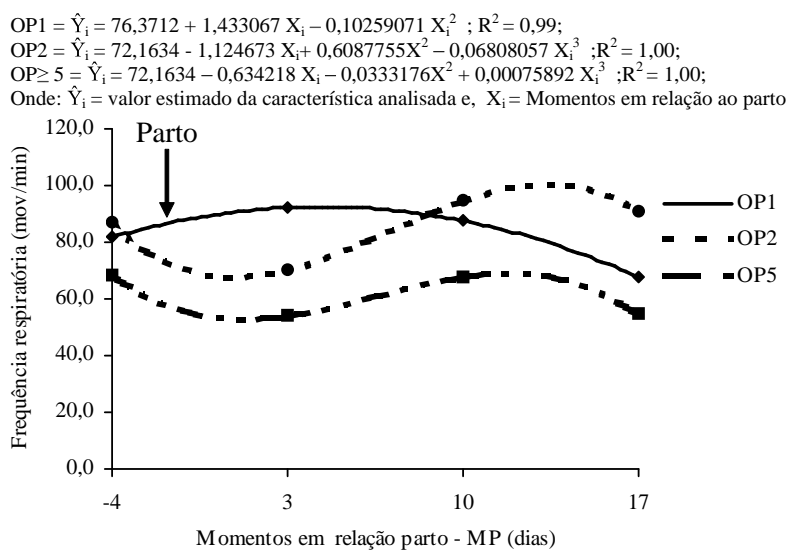

Figura 5 - Frequiência respiratória (mov/min) de matrizes suínas híbridas, em função do efeito do momento em relação ao parto dentro da ordem do parto.

Verificou-se interação entre horas do dia e ordem do parto (Tabela 6), sendo observados efeitos quadráticos $(\mathrm{P}<0,05)$ da hora do dia sobre a FR, dentro das ordens de parto (Figura 6).

Considerando que as matrizes sob conforto térmico mantém a FR entre 26 e $27 \mathrm{mov} / \mathrm{min}$, é bem provável que essas tenham estado em desconforto térmico, uma vez que exibiram taquipnéia durante todas as horas avaliadas. Isso é bastante sugestivo de um processo de aclimatação quando os resultados são comparados com os relatados na literatura para matrizes mantidas sob estresse térmico, em câmaras climáticas (RENAUDEAU et al., 2001; SPENCER et al., 2003).
$\mathrm{OP} 1=\hat{\mathrm{Y}}_{\mathrm{i}}=-37,0400+18,958567 \mathrm{X}_{\mathrm{i}}-0,675889 \mathrm{X}_{\mathrm{i}}^{2} ; \mathrm{R}^{2}=0,99 ;$ $\mathrm{OP} 2=\hat{\mathrm{Y}}_{\mathrm{i}}=-37,0400+20,614542 \mathrm{X}_{\mathrm{i}}-0,767406 \mathrm{X}_{\mathrm{i}}^{2} ; \mathrm{R}^{2}=0,99 ;$ $\mathrm{OP} 3=\hat{\mathrm{Y}}_{\mathrm{i}}=-37,0400+18,039148 \mathrm{X}_{\mathrm{i}}-0,658798 \mathrm{X}_{\mathrm{i}}^{2} ; \mathrm{R}^{2}=0,90 ;$ $\mathrm{OP} 4=\hat{Y}_{\mathrm{i}}=-37,0400+18,779654 \mathrm{X}_{\mathrm{i}}-0,716024 \mathrm{X}_{\mathrm{i}}^{2} ; \mathrm{R}^{2}=0,97$; $\mathrm{OP} \geq 5=\hat{\mathrm{Y}}_{\mathrm{i}}=-37,0400+16,921142 \mathrm{X}_{\mathrm{i}}-0,644064 \mathrm{X}_{\mathrm{i}}^{2} ; \mathrm{R}^{2}=0,97 ;$ Onde: $\hat{Y}_{i}=$ valor estimado da característica analisada e $X_{i}=$ hora do dia

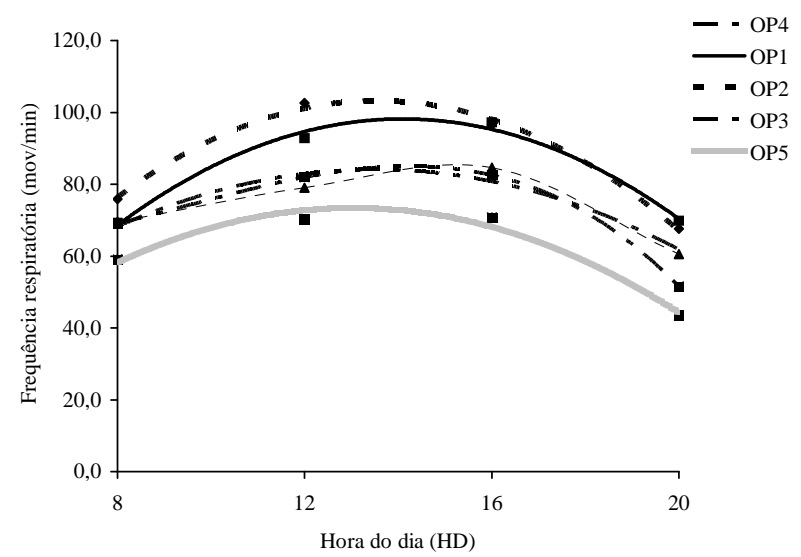

Figura 6-Freqüência respiratória (mov/min) de matrizes suínas híbridas, em função do efeito da hora do dia dentro da ordem do parto.

Houve interação $(\mathrm{P}<0,05)$ entre momento em relação ao parto e horas do dia, para FR (Tabela 7). A análise de regressão constatou efeito quadrático $(\mathrm{P}<0,05)$ do momento em relação ao parto, sobre a FR dos animais avaliados às 8 $\mathrm{h}$, e efeito cúbico $(\mathrm{P}<0,05)$ para as mensurações realizadas às 12,16 e 20 horas (Figura 7).

Constatou-se, nos quatro momentos em relação ao parto, a ocorrência de efeitos quadráticos $(\mathrm{P}<0,05)$ sobre a FR dos animais (Figura 8), que apresentou um coeficiente de variação alto $(43,53 \%)$ podendo ser justificado pela dificuldade de observar os animais e quantificar os valores, nos horários mais quentes do dia e/ou nos momentos antes do parto, quando o metabolismo estava mais intenso.

Tabela 6 - Média da freqüência respiratória (mov/min) de matrizes suínas híbridas em função da interação entre hora do dia e ordem do parto.

\begin{tabular}{|c|c|c|c|c|c|c|}
\hline \multirow{2}{*}{$\begin{array}{l}\text { Momento em } \\
\text { relação ao parto } \\
\text { (dias) }^{1}\end{array}$} & \multicolumn{5}{|c|}{ Ordem do parto } & \multirow[b]{2}{*}{ Média } \\
\hline & $1^{\mathrm{a} 2}$ & $2^{\mathrm{a} 3}$ & $3^{\mathrm{a}}$ & $4^{\mathrm{a}}$ & $\geq 5^{\mathrm{a}^{3}}$ & \\
\hline-4 & $81,75 \pm 41,24 a$ & $86,96 \pm 35,70 a$ & $79,02 \pm 34,26 a$ & $75,81 \pm 31,99 \mathrm{a}$ & $68,70 \pm 30,31 a$ & 78,45 \\
\hline $3^{\circ}$ & $92,23 \pm 40,10 a$ & $70,33 \pm 46,07 b$ & $72,40 \pm 32,84 b$ & $67,46 \pm 36,04 b$ & $54,22 \pm 30,41 \mathrm{c}$ & 71,33 \\
\hline $10^{\circ}$ & $87,58 \pm 34,52 a$ & $94,67 \pm 40,79 a$ & $70,89 \pm 32,18 b$ & $70,21 \pm 33,69 b$ & $67,89 \pm 33,11 b$ & 78,25 \\
\hline $17^{\circ}$ & $67,76 \pm 67,76 b$ & $90,83 \pm 37,13 a$ & $71,18 \pm 28,72 b$ & $72,75 \pm 34,71 b$ & $54,54 \pm 27,43 c$ & 71,41 \\
\hline Média & 82,33 & 85,70 & 73,37 & 71,56 & 61,34 & 74,86 \\
\hline
\end{tabular}

Médias seguidas da mesma letra (linhas), não diferem significativamente entre si pelo teste de Tukey $(\mathrm{P}<0,05)$.

${ }^{1}$ Efeito quadrático $(\mathrm{P}<0,05)$ 
Tabela 7 - Média da freqüência respiratória (mov/min) de matrizes suínas hibridas em função da interação entre momentos em relação ao parto e hora do dia.

\begin{tabular}{|c|c|c|c|c|c|}
\hline \multirow{2}{*}{$\begin{array}{l}\text { Momentos em } \\
\text { relação ao parto } \\
(\text { dias) })^{1}\end{array}$} & \multicolumn{4}{|c|}{ Hora do dia } & \multirow[b]{2}{*}{ Média } \\
\hline & $8^{2}$ & $12^{3}$ & $16^{3}$ & $20^{3}$ & \\
\hline-4 & $79,12 \pm 32,53 b$ & $93,21 \pm 31,32 \mathrm{a}$ & $90,98 \pm 30,23 \mathrm{a}$ & $49,93 \pm 30,78 \mathrm{c}$ & 78,31 \\
\hline $3^{\circ}$ & $55,97 \pm 30,34 \mathrm{~b}$ & $85,75 \pm 37,79 a$ & $86,76 \pm 40,02 \mathrm{a}$ & $60,41 \pm 36,87 b$ & 72,22 \\
\hline $10^{\circ}$ & $71,38 \pm 37,10 b c$ & $81,13 \pm 35,19 b$ & $91,69 \pm 33,34 \mathrm{a}$ & $64,11 \pm 31,30 \mathrm{c}$ & 77,08 \\
\hline $17^{\circ}$ & $68,10 \pm 30,66 a$ & $79,00 \pm 33,28 \mathrm{a}$ & $76,14 \pm 31,24 \mathrm{a}$ & $57,18 \pm 29,28 \mathrm{~b}$ & 70,10 \\
\hline Média & 68,64 & 84,77 & 86,39 & 57,91 & 74,43 \\
\hline
\end{tabular}

${ }^{1}$ Os números: $-4,3^{\circ}, 10^{\circ}$ e $17^{\circ}$, corresponderam os momentos em relação ao parto (dias) em que foram realizadas as mensurações, sendo o parto o dia 0 .

Médias seguidas da mesma letra (linhas), não diferem significativamente entre si pelo teste de Tukey $(\mathrm{P}<0,05)$

${ }^{2}$ Efeito quadrático $(\mathrm{P}<0,05)$

${ }^{3}$ Efeito cúbico $(\mathrm{P}<0,05)$

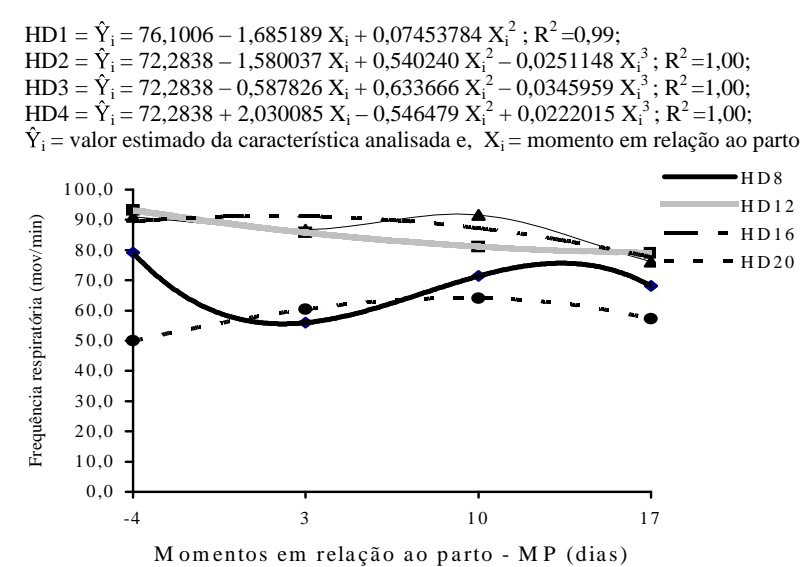

Figura 7 - Freqüência respiratória (mov/min) de matrizes suínas híbridas, em função do efeito do momento em relação ao parto e da hora do dia (HD).

Os coeficientes de correlação (r) entre as variáveis fisiológicas e ambientais (Tabela 8) indicaram correlação baixa positiva entre TR com a temperatura ambiente, mas uma correlação baixa negativa entre TR e UR. Por sua vez, a FR apresentou correlação baixa positiva com a temperatura ambiente, do globo e com o ITGU e negativa com a UR. Presume-se, que a FR seja mais vulnerável às variações ambientais, especialmente temperatura, sendo este mecanismo, o mais importante para dissipação de calor e manutenção da homeotermia, em matrizes suínas lactantes.

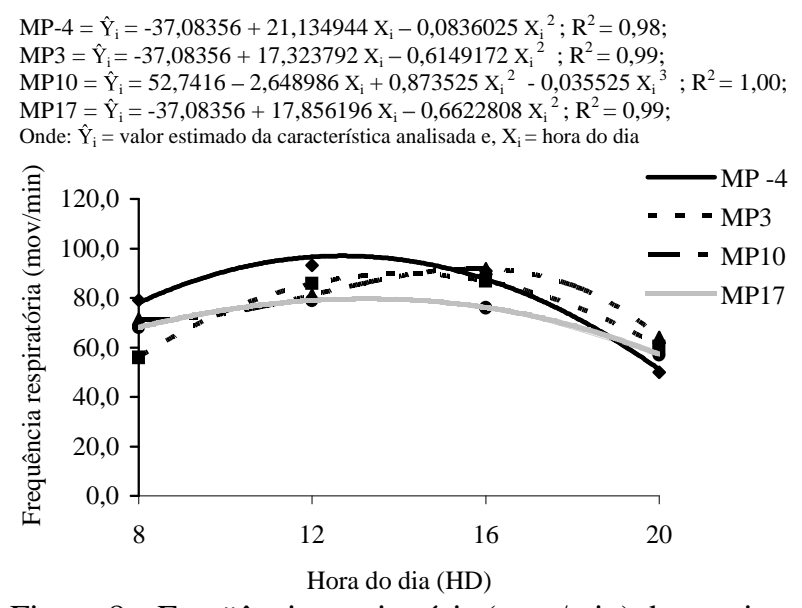

Figura 8 - Freqüência respiratória (mov/min) de matrizes suínas híbridas, em função do efeito da hora do dia dentro do momento em relação ao parto.

Tabela 8 - Matriz de correlações entre as variáveis: temperatura retal (TR), freqüência respiratória (FR), temperatura ambiente (Ta), temperatura de globo $(\mathrm{Tg})$, umidade relativa do ar (UR) e índice de temperatura de globo e umidade (ITGU).

\begin{tabular}{ccccccc}
\hline Variáveis & TR & FR & Ta & Tg & UR & ITGU \\
\hline TR & - & $0,398^{*}$ & $0,104^{*}$ & $-0,018$ & $-0,103^{*}$ & $-0,026$ \\
FR & & - & $0,346^{*}$ & $0,297^{*}$ & $-0,340^{*}$ & $0,286^{*}$ \\
\hline
\end{tabular}

*Significativo em nível de $5 \%$ de probabilidade pelo teste $\mathrm{t}$ de Student. 


\section{CONCLUSÕES}

Matrizes suínas híbridas em lactação aumentam a temperatura retal e a frequiência respiratória nos períodos de pico de calor diários (12 a 16h), demonstrando baixa adaptabilidade ao estresse calórico. Diante disso, essas fêmeas podem ser criadas em ambientes com temperatura acima do conforto térmico, desde que sejam adotadas medidas para minimizar o estresse calórico no turno da tarde, principalmente para primíparas.

\section{REFERÊNCIAS BIBLIOGRÁFICAS}

BLACK, J. L.; MULLAN, B. P.; LORSCHY, M. L. Lactation in the sow during heat stress. Livestock Production Science, Amsterdam, v. 35, n. 1, p. 153-170, 1993.

BUFFINGTON, D. E.; COLAZZO-AROCHO, A.; CANTON, C. H. Black globe-humidity index (BGHI) as comfort equation for dairy cows. Transaction of the ASAE, Amsterdam, v. 24, p. 711-714, 1981.

GOMES, F. P. Curso de estatística. 11. ed. Piracicaba: Nobel, 1985. 466 p.

GÖRANSSON, L. The effect of feed allowance in late pregnancy on the occurrence of agalactia post partum in the sow. Journal of Veterinary Medicine, [S.1.], v. 36, p. 505-513, 1989.

KELLY, K. W.; CURTIS, S. E. Effects of heat stress on rectal temperature, respiratory rate and activity rates in peripartal sows and gilts, Journal of Animal Science, Champaign, v. 46, n. 2, p. 356-360, 1978.

QUINIOU, N.; NOBLET, J. Influence of high ambient temperatures on performance of multiparous lactating sows. Journal of Animal Science, Champaign, v. 77, n. 8, p. 21242134, 1999.

RENAUDEAU, D.; QUINIOU, N.; NOBLET, J. Effects of exposure to high ambient temperature and dietary protein level on performance of multiparous lactating sows. Journal of Animal Science, Champaign, v. 79, n. 5, p. 1240-1249, 2001.

SAINT PIERRE, N. R.; COBANOV, B.; SCHNITKEY, G. Economic losses from heat stress by US livestock industries. Journal of Dairy Science, Champaign, v. 86, p. 52-77, 2004. Supplement.

SAS INSTITUTE. User's guide: statistics. Versão 6.12. Cary: North Carolina State University, 1997. CD-ROM.

SPENCER, J. D.; BOYD, R. D.; CABRERA, R. Early weaning to reduce tissue mobilization in lactating sows and milk supplementation to enhance pigs weaning weight during extreme heat stress. Journal of Animal Science, Champaign, v. 81, n. 8, p. 2041-2052, 2003.

TURCO, S. H. N.; FERREIRA, A. S.; OLIVEIRA, R. F. M. Desempenho de porcas e leitões em maternidades com diferentes sistemas de acondicionamento térmico no inverno. Revista Brasileira de Zootecnia, Viçosa, v. 27, n. 5, p. 988-993, 1998. 